\title{
The Acceptance of the English Language Learning Mobile Application Hello English Across Gender and Experience Differences
}

\author{
https://doi.org/10.3991/ijet.v15i15.11077 \\ I Dewa Gede Rat Dwiyana Putra ( $\left.{ }^{\bowtie}\right)$, Ali Saukah, \\ Yazid Basthomi, Enny Irawati \\ Universitas Negeri Malang, East Java, Indonesia \\ ratdwiyanaputra@gmail.com
}

\begin{abstract}
This study is aimed at investigating the relationship between students' perceived effect (PE) and their intention to use (IU) one of the English language learning mobile applications which is called Hello English, and also the differences of students' PE and IU based on gender and experience. There are 24 male and 73 female students who completed the online survey which was administered to several universities in Indonesia. The result of a bivariate correlation analysis shows a statistically significant positive relationship between students' PE and IU, where gender differences do not have any significant influence on their PE and IU. On the other hand, students who have experienced using Hello English for more than three months perceived the effect of Hello English on their communicative competence better than those who only use it less than three months. Besides, the experienced users also show a higher intention to use Hello English to learn English in the future.
\end{abstract}

Keywords-Language learning, mobile application, educational technology.

\section{Introduction}

The integration of Information and Communication Technology (ICT) for the academic purposes raises an issue of technology acceptance, which becomes an interesting field of investigation for many scholars across the globe [1]-[4]. Technology Acceptance Model (TAM) is one of the pioneering theories which aims to determine behaviors of users towards particular technologies by employing two factors: perceived usefulness and perceived ease of use. It has been proven to be a strong framework to explain the technology integration acceptance in various fields [5]-[7]. TAM framework hypothesized that: a) the users' behavioral intention would determine the actual use of a computer system; b) users' perceived usefulness and attitude would determine the users' behavioral intention to use computer system; c) perceived usefulness and perceived ease of use would determine users' attitude toward using computer system; and d) perceived usefulness is determined by perceived ease of use, and 
it act as a mediating variable between users' perceived ease of use and attitude [5], [6], [8].

Based on the recent development of TAM, studies on technology acceptance in general education field all around the world primarily focus on the students' acceptance in using mobile-based learning technology [2], [9]-[15] and e-learning system [4], [16]-[18]. Most of the studies were done by investigating the relationship of various external variables with intention to use mobile technology, i.e. mobility, interactivity, and enjoyment [11], perceived convenience [14], perceived potential of mobile-based language learning, preference in learning, and students' self-management [15], quality of service [2]. However, studies that investigate the specific external variables, such as the perceived effect of a mobile-based applications, specifically developed for specific users of a specific environment, e.g. English language learning, are rarely explored.

The perceived effect (PE) itself can be defined by examining the means by which it was operationalized [19], [20]. In this study, the investigated variable is the perceived effect of a particular mobile-based application on communicative competence. Thus, $\mathrm{PE}$ can be defined as "an estimate of the degree to which a mobile-based application will be favorably evaluated, in terms of its persuasive potential in improving communicative competence, by the users of that application." This definition of PE is actually similar to perceived usefulness (PU) which is defined as "the degree to which a person believes that using a particular system would enhance his or her job performance" [5], [21].

The students' perceived effect of using Hello English is elicited based on the six components of communicative competence as cited in [22], including: (a) sociocultural competence deals with the knowledge of language use both socially and culturally. It requires the language user to have a pragmatic knowledge, in order to be able to communicate appropriately based on a certain context, (b) discourse competence is the ability to produce a complete and fluent speech from a fine identification and selection of lexical items and appropriate use of language structures, (c) linguistic competence is the basic requirement to master a language, which refers to the knowledge of sound system, words and grammar, (d) formulaic competence is the ability to identify the language-specific lexicalization system that is commonly used in the real communication, e.g. collocations, phrasal verbs, and idioms, (e) interactional competence is the ability of the language users to initiate and interact actively in a communication, and (f) strategic competence is the language users' capacity to select and apply a particular strategy both in learning and using the language.

Hello English (from: https://helloenglish.com/) is a mobile-based application which is specially developed to assist the users in learning English interactively. The application can be downloaded and installed in Android, Windows, Web and Apple operating systems. There are up to 475 interactive lessons and games which are related to language components, skills and usage. It also provides 10.000 words bilingual dictionary, available in 22 languages. Hello English provides 'homework' as a daily task that is updated based on the last finished lesson. There are also independent tasks including interactive conversation, reading comprehension, games, pronunciation, and listening comprehension. Progress can be monitored in accomplishing the lessons and 
compare it with other users in the forum. Hello English also provides pre-paid advanced interactive courses with a real teacher, language services, and English certification services. This application is the Google editors' choice in 2017 and reached more than 40 million users around the world in early 2018.

Besides investigating the extension of TAM framework variables, i.e. perceived usefulness (PU) and perceived ease of use (PEOU), mobile technology acceptance researchers also studied the role of gender in explaining variables predicting users' intention to use mobile technology, since gender is one of the variables that theoretically moderate the relationship between the external variables and users' intention [23]. Gender was also found as a moderating variable of online game acceptance [24]. However, other studies, that investigate the role of gender on mobile technology acceptance, found that gender differences do not have any influence on both external variables and users' intention [9], [12], [25]. In this study, gender is also used to categorize the PE and IU, so we can compare them to see whether users' PE and IU are different due to gender differences.

Studies done in the area of mobile technology acceptance also revealed that experience plays a significant role in explaining users' intention. An increasing experience in using a particular mobile technology will enable the users to get more information on how effective, easy or difficult the system is, reduce anxiety, and improve the intention to use the technology [25]-[27]. However, studies focused on investigating the role of experience in differentiating users' perceived effect and intention are relatively rare [21]. Therefore, an investigation on the differences between the perceived effect of using Hello English and intention to use mobile technology based on experience would be beneficial to explain users' acceptance of the mobile technology.

Given the aforementioned gaps, this study aims at investigating the relationship between users' perceived effect (PE) of Hello English on communicative competence and the intention to use (IU) Hello English and also the differences of users' PE and IU based on gender and experience differences. The results of this study are expected to give evidence on the relationship of PE and IU and explain how gender and experience differentiate students' perceived effect and intention to use mobile technology in learning English.

\section{Approach}

97 Hello English users (24 males and 73 females) completed the online survey which was administered at several universities around Indonesia, including Sumatera, Java, Bali and Nusa Tenggara Timur. In terms of users' experience, 74 respondents have experienced using Hello English mobile application for less than 3 months, while the rest (23 respondents) for more than 3 months.

The full questionnaire for this study comprised 4 parts. The first part (item 1-2) investigates whether the students use Hello English or not because only users who can continue answering the rest of the questionnaire. In the first part, the respondent email is required for the purpose of future follow up interview. The second part (item 3-6) includes items measuring students' length of experience (EX) in using Hello English 
and their usage frequency. For the purpose of this study, the participants' experience was assessed by item number 4 which differentiate the experience into: a. less than 1 month, b. 1-3 months, c. 3-6 months, d. 6-12 months, e. more than 1 year, and one short answer provided for the length of experience which is not listed.

The second part of the questionnaire consists of 20 questions that measures participants' Perceived Usefulness (PU; item 1-12), Perceived Ease of Use (PEOU; item 1318), Attitudes (ATT; item 19-22), and Intention to Use (IU; item 23-26) ELLMA (Hello English) based on five-point Likert scale, ranging from 1 (strongly disagree) to 5 (strongly agree). For the purpose of this study, only 4 items of IU (23-26), which are analyzed to see the participants' intention differences across gender and experience.

Part 3 of this questionnaire assesses the participants' perceived effect (PE) of using Hello English on communicative competence. For this purpose, the questionnaire provides $15 \mathrm{yes} /$ no questions of PE based on the combination of perceived usefulness (PU) of ELLMA as cited in [7], toward communicative competence as cited in [22]. The participants' PE score range from $0-15$, where 0 means that the participant does not perceive any positive effect of ELLMA on any aspect of the communicative competence, and 15 means that the students perceived positive effect in all of the aspects of communicative competence. The last part requires the respondents to give information regarding their demographic data including sex, age, level of education, etc. table 1 provide the questionnaire items calculation guideline for this study.

Table 1. Questionnaire Items Calculation Guideline

\begin{tabular}{|l|c|c|l|l|l|}
\hline Variables & Items Number & $\mathbf{n}$ & \multicolumn{1}{|c|}{ Measure } & \multicolumn{1}{c|}{ Type } & \multicolumn{1}{c|}{ Code/Score } \\
\hline Gender & 30 & 1 & Categorical & Short Answer & Male $=1$, Female $=0$ \\
\hline Experience & 4 & 1 & Categorical & Short Answer & $\begin{array}{l}<3 \text { months }=1 \\
>3 \text { months }=2\end{array}$ \\
\hline IU & $23-26$ & 4 & Numerical & 5 levels Likert Scale & $\begin{array}{l}\text { Strongly agree }=5, \\
\text { agree }=4, \text { undecided }= \\
\text { 3, disagree }=2, \text { strongly } \\
\text { disagree }=1\end{array}$ \\
\hline PE & $\begin{array}{c}27 \\
(27 . a-27.0)\end{array}$ & 15 & Numerical & Yes/No Question & Yes $=1$, No $=0$ \\
\hline
\end{tabular}

Prior to the survey, 14 English lecturers were asked to respond to the questionnaire and give feedback about the language clarity. The result indicated that there were several minor revisions on the language used in the questionnaire items. Both PE and IU items reliability were also assessed using Cronbach's Alpha coefficient. Items for PE show a high value of Cronbach's Alpha (.929) which shows an excellent internal consistency, while IU items also show a good internal consistency with Cronbach's Alpha (.873).

The survey data were analyzed as follows: First, raw data contain all responses from the online questionnaire were transformed into numbers in excel sheet. First, the two categorical data, i.e., participants' sex and experience are coded. The participants' length of experience is divided into two categories, that are less than three months coded by ' 1 ' and more than three months coded by ' 2 '. Male participants are coded by ' 1 ' and female participants by ' 0 '. Then, the participants PE score is ' 1 ' for every 
'yes' and '0' for every 'no' answer. The PE score range from $0=$ all answers 'no' to $15=$ all answers 'yes'. Finally, the IU scores are: strongly agree $=5$, agree $=4$, undecided $=3$, disagree $=2$, and strongly disagree $=1$. IU scores ranges from 4 means all answered strongly disagree to 20 means all answered strongly agree.

Thereafter, SPSS was utilized to run descriptive statistics calculation to determine the distributional characteristics of each variable. Next, the relationship between PE and IU was examined, and also the value of PE and IU based on the respondents' gender and experience was compared.

\section{$3 \quad$ Findings}

The result of a bivariate correlation analysis displays a statistically significant positive relationship between the perceived effect (PE) and intention to use (IU) Hello English among respondents $(\mathrm{r}=0.464, \mathrm{p}<.001)$. This positive correlation between two variables indicates that if students' perceived effect (PE) increases, intention to use (IU) will also increase. The results of correlation analysis are provided in Table 1.

Table 2. Correlation between Perceived Effect (PE) and Intention to Use (IU) Hello English

\begin{tabular}{|c|c|c|c|c|}
\hline & & & PE & IU \\
\hline \multirow{6}{*}{ Spearman's rho } & \multirow{3}{*}{$\mathrm{PE}$} & Correlation Coefficient & 1.000 & $.464^{* *}$ \\
\hline & & Sig. (2-tailed) & . & .000 \\
\hline & & $\mathrm{N}$ & 97 & 97 \\
\hline & \multirow{3}{*}{$\mathrm{IU}$} & Correlation Coefficient & $.464^{* *}$ & 1.000 \\
\hline & & Sig. (2-tailed) & .000 & . \\
\hline & & $\mathrm{N}$ & 97 & 97 \\
\hline
\end{tabular}

**. Correlation is significant at the 0.01 level (2-tailed).

Mann-Whitney U test analysis was conducted to examine whether the perceived effect and intention to use Hello English are different between male and female students. The results in Table 2 show that gender differences did not have any significant influence on both PE and IU among the respondents.

Table 3. Results of Mann-Whitney U test analysis on PE and IU based on Gender

\begin{tabular}{|l|l|c|c|c|c|c|}
\hline & Gender & N & Mean Rank & Sum of Ranks & *Mann-Whitney U & Sig. (2-tailed) \\
\hline \multirow{4}{*}{ PE } & Male & 24 & 49.56 & 1189.50 & 862.500 & .908 \\
\cline { 2 - 8 } & Female & 73 & 48.82 & 3563.50 & & \\
\cline { 2 - 8 } & Total & 97 & & & & \\
\hline \multirow{3}{*}{ IU } & Male & 24 & 42.54 & 1021.00 & 721.000 & .181 \\
\cline { 2 - 8 } & Female & 73 & 51.12 & 3732.00 & & \\
\cline { 2 - 7 } & Total & 97 & & & & \\
\hline
\end{tabular}

*Grouping Variable: Gender

Mann-Whitney U test analysis was performed again to evaluate the PE and IU differences between the respondents who have experienced using Hello English for less than 3 months and more than 3 months. The results show significant differences of 
perceived effect $(P E)(U=506, p<0.01)$ and intention to use $(U=557, p<0.05)$ between the two groups. These findings suggest that users' experience had some influence on the perceived effect of Hello English which also influence their intention to use it as shown in Table 3.

Table 4. Results of Mann-Whitney $U$ test analysis on PE and IU based on Experience

\begin{tabular}{|l|l|c|c|c|c|c|}
\hline & \multicolumn{1}{|c|}{ EX } & N & Mean Rank & Sum of Ranks & Mann-Whitney U & Sig. (2-tailed) \\
\hline \multirow{4}{*}{ PE } & $<3$ Months & 74 & 44.34 & 3281.00 & 506.000 & .003 \\
\cline { 2 - 7 } & $>3$ Months & 23 & 64.00 & 1472.00 & & \\
\cline { 2 - 7 } & Total & 97 & & & & \\
\hline \multirow{3}{*}{ IU } & $<3$ Months & 74 & 45.03 & 3332.50 & 557.500 & .010 \\
\cline { 2 - 7 } & $>3$ Months & 23 & 61.76 & 1420.50 & & \\
\cline { 2 - 7 } & Total & 97 & & & & \\
\hline
\end{tabular}

*Grouping Variable: Experience

\section{Discussion}

This study aims at exploring the students' intention to use (IU) Hello English as an English language learning mobile application. The significant positive relationship between students' perceived effect (PE) and intention to use (IU) Hello English is the first finding of this study. This relationship indicates that students who perceived the benefit of Hello English mobile application on their communicative competence will most likely continue to use it to learn English in the future. In this study, the perceived effect on communicative competence could probably become the specific form of 'performance expectancy' construct of UTAUT [23], since it also reflects the degree of students' beliefs that using Hello English mobile application will improve their communicative competence.

Previous research findings as cited in [4], [9], [10] show a similar positive result where 'performance expectancy' is a strong determiner of students' intention to use smartphone as learning tools. However, previous studies mainly focus on the smartphone as a device/hardware to assist learning and do not give a specific emphasis on the software/application which is specifically developed for a certain field of study, e.g. English language learning. The present study proves that students' perceived effect as a form of performance expectancy is also applicable to explain not only students' intention to use smartphone as the hardware of mobile learning but also the mobile learning application as a specific software developed for English language learning. Moreover, the perceived effect could be specified based on the function of the mobile application, where in this case, since the application is specifically developed for English language learning, the perceived effect is specified on students' communicative competence.

The second finding of this study reveals that gender differences do not influence the users' perceived effect of Hello English on their communicative competence, and also their intention to use Hello English mobile application. These findings also confirm the results from previous studies which found that female and male participants 
perceived the same usefulness of mobile learning and show similar acceptance and intention to use mobile technology [9], [25], [28]. Thus, it is evident that English language learning mobile application could be disseminated equally for students' regardless of their gender differences because they would accept the application in the same way. Furthermore, mobile learning could also become a means to exchange and share knowledge among students where they are separated based on gender differences throughout each level of education [10].

The last finding deals with the differences between students' perceived effect and intention to use Hello English based on their experience in using the application. In this study, students who have been using Hello English for more than three months perceived the effect of the application on their communicative competence better than those who only use it for less than three months. Moreover, the experienced users also show a higher intention to use Hello English in the future. This finding supports the results of previous studies which identify that as the users increase their experience in using a technology, they will find that the technology is user friendly and useful, which will also increase their intention to use the technology [9], [10], [25], [28]. It suggests that higher intention to use a particular language learning mobile application may occur after prolonged and regular usage, up to the point where the users believes that it would be beneficial for enhancing their communicative competence. Therefore, it is important to provide clear instructions and close assistance when introducing a new application specially for learning purposes.

\section{Conclusion and Recommendation}

Studies that investigate students' intention in using mobile application specifically developed for English language learning are limited. The majority of previous studies do not emphasize on the specification of the mobile learning application based on the subject matter and users. Therefore, it is envisaged that this study will contribute to the existing knowledge by providing three main conclusions. First, students' intention to use mobile learning application could be explained based on the students' perceived effect of the application on their competence. Second, mobile learning application acceptance is similar among gender groups, where female and male students perceived the same effect and also embrace the same intention to use mobile learning application. Therefore, it is recommended that the teacher or any educational organizer disseminates the mobile learning application equally for both male and female students as early as possible, so that they can interact and collaborate through the application to improve their knowledge. Third, as the students improve their experience in using the application, they would be able to get used to the application which will improve their perceived effect and intention to use the application.

There are several limitations of this study that would inspire the direction of future research. The findings about differences of the perceived effect (PE) and intention to use (IU) language learning mobile application among the participants are compared based on the usage length discrepancies only. Other classification, e.g. education level or technology familiarity might be able to provide a more comprehensive result. Fur- 
ther studies should also involve other external variables of the Unified Theory of Acceptance and Use of Technology (UTAUT2) suggested by [29], [30]. In this study, we explored only some variables that explain students' intention to use mobile application, but a more comprehensive study that incorporates all possible related variables of UTAUT 2 is expected to provide more powerful contribution to the existing knowledge of mobile technology and application acceptance. We also encourage other researchers to replicate this study in different context, which would yield a more generalizable findings and give positive implication on the development of mobile learning application and mobile learning practice among students, teacher and other ELT practitioners across the globe.

\section{References}

[1] H. Liu, C.-H. Lin, and D. Zhang, "Pedagogical beliefs and attitudes toward information and communication technology: a survey of teachers of English as a foreign language in China," Comput. Assist. Lang. Learn., vol. 30, no. 8, pp. 1-21, 2017.

[2] B. Lebzar and R. Jahidi, "Factors Influencing the Acceptance of M-Learning by Students of Higher Education in Morocco," Int. J. Emerg. Res. Manag. \&Technology, vol. 6, no. 6, pp. 2278-9359, 2017. **. Correlation is significant at the 0.01 level (2-tailed).

[3] A. Kashada, H. Li, and O. Koshadah, "Analysis approach to identify factors influence digital learning technology adoption and utilization in developing countries," Int. J. Emerg. Technol. Learn., vol. 13, no. 2, pp. 48-59, 2018. https://doi.org/10.3991/ijet.v13i02.7399

[4] S. S. Binyamin, M. J. Rutter, and S. Smith, "Extending the technology acceptance model to understand students' use of learning management systems in Saudi higher education," Int. J. Emerg. Technol. Learn., vol. 14, no. 3, pp. 4-21, 2019. https://doi.org/10.3991/ijet. $\underline{\mathrm{v} 14 \mathrm{i} 03.9732}$

[5] F. J. Rondan-Cataluña, J. Arenas-Gaitán, and P. E. Ramírez-Correa, "A comparison of the different versions of popular technology acceptance models a non-linear perspective," Kybernetes, vol. 44, no. 5, pp. 788-805, 2015. https://doi.org/10.1108/k-09-2014-0184

[6] P. Lai, "the Literature Review of Technology Adoption Models and Theories for the Novelty Technology,” J. Inf. Syst. Technol. Manag., vol. 14, no. 1, pp. 21-38, 2017.

[7] F. Davis, "Perceived usefulness, perceived ease of use, and user acceptance of information technology,” MIS Q., vol. 13, no. 3, pp. 319-340, 1989. https://doi.org/10.2307/249008

[8] F. D. Davis, R. P. Bagozzi, and P. R. Warshaw, "User Acceptance of Computer Technology: A Comparison of Two Theoretical Models," Manage. Sci., vol. 35, no. 8, pp. 9821003, 1989. https://doi.org/10.1287/mnsc.35.8.982

[9] M. S. Ahmed and A. Kabir, "The Acceptance of Smartphone as a Mobile Learning Tool: Students of Business Studies in Bangladesh," Malaysian Online J. Educ. Technol., vol. 6, no. 2, pp. 38-47, 2018. https://doi.org/10.17220/mojet.2018.02.003

[10] O. Alharbi, H. Alotebi, A. Masmali, and N. Alreshidi, "Instructor Acceptance of Mobile Learning in Saudi Arabia: A Case Study of Hail University,” Int. J. Bus. Manag., vol. 12, no. 5 , p. 27,2017 . https://doi.org/10.5539/ijbm.v12n5p27

[11] R. A. Ali, M. Rafie, and M. Arshad, "Perspectives of Students' Behavior Towards Mobile Learning (M-learning) in Egypt: an Extension of the UTAUT Model," Eng. Technol. Appl. Sci. Res., vol. 6, no. 4, pp. 1108-1113, 2016. 
[12] N. J. Alzaidiyeen, "English as a Foreign Language Students Attitudes towards the Utilization of iPad in Language Learning," Malaysian Online J. Educ. Technol., vol. 5, no. 3, pp. 16-24, 2017.

[13] J. G. Chaka and I. Govender, "Students' perceptions and readiness towards mobile learning in colleges of education: a Nigerian perspective," South African J. Educ., vol. 37, no. 1, pp. 1-12, 2017. https://doi.org/10.15700/saje.v37n1a1282

[14] C.-C. Chang, C.-F. Yan, and J.-S. Tseng, "Perceived convenience in an extended technology acceptance model: Mobile technology and English learning for college students," Australas. J. Educ. Technol., vol. 28, no. 5, pp. 809-826, 2012. https://doi.org/10.14742/ajet.81 $\underline{8}$

[15] H. Hashim, M. M. Yunus, and M. A. Embi, "Pre-University English as Second Language (ESL) Learners' Attitude towards Mobile Learning," Creat. Educ., no. June, pp. 11471153, 2016. https://doi.org/10.4236/ce.2016.78119

[16] M. M. Abbad and F. N. Jaber, "Evaluating e-learning systems: An empirical investigation on students' perception in higher education area," Int. J. Emerg. Technol. Learn., vol. 9, no. 4, pp. 27-34, 2014. https://doi.org/10.3991/ijet.v9i4.3480

[17] A. Alenezi, "Checking on preferential choices of e-learning \& mlearning: A case study of Northern Border University, Saudi Arabia," Int. J. Emerg. Technol. Learn., vol. 12, no. 5, pp. 98-116, 2017. https://doi.org/10.3991/ijet.v12i05.6790

[18] R. A. S. Al-Maroof and M. Al-Emran, "Students acceptance of google classroom: An exploratory study using PLS-SEM approach,” Int. J. Emerg. Technol. Learn., vol. 13, no. 6, pp. 112-123, 2018. https://doi.org/10.3991/ijet.v13i06.8275

[19] J. P. Dillard, K. M. Weber, and R. G. Vail, "The relationship between the perceived and actual effectiveness of persuasive messages: A meta-analysis with implications for formative campaign research,” J. Commun., vol. 57, no. 4, pp. 613-631, 2007. https://doi.org/10. 1111/j.1460-2466.2007.00360.x

[20] J. P. Dillard and S. Ye, "The perceived effectiveness of persuasive messages: Questions of structure, referent, and bias," J. Health Commun., vol. 13, no. 2, pp. 149-168, 2008. https ://doi.org/10.1080/10810730701854060

[21] V. Venkatesh, J. Y. L. Thong, B. Statistics, X. Xu, and T. Acceptance, "Unified Theory of Acceptance and Use of Technology: A Synthesis and the Road Ahead," Jais, vol. 17, no. 5, pp. 328-376, 2016. https://doi.org/10.17705/1jais.00428

[22] M. Celce-murcia, "Rethinking the Role of Communicative Competence in Language Teaching," in Intercultural Language Use and Language Learning, E. A. Soler and M. P. S. Jordà, Eds. Netherland: Springer, 2007, pp. 41-58. https://doi.org/10.1007/978-1-4020-56 $\underline{39-0} 3$

[23] V. Venkatesh, M. G. Morris, G. B. Davis, and F. D. Davis, "User Acceptance of Information Technology: Toward a Unified View,” Source MIS Q., vol. 27, no. 3, pp. 425-478, 2003. https://doi.org/10.2307/30036540

[24] M. C. Lee, "Understanding the behavioural intention to play online games: An extension of the theory of planned behaviour," Online Inf. Rev., vol. 33, no. 5, pp. 849-872, 2009. https://doi.org/10.1108/14684520911001873

[25] S. Belgheis and R. Kamalludeen, "The Intention to Use GeoGebra in the Teaching of Mathematics among Malaysian Teachers,” Malaysian Online J. Educ. Technol., vol. 6, no. 1, pp. 109-115, 2018.

[26] V. Venkatesh, "Determinants of Perceived Ease of Use : Integrating Control, Intrinsic Motivation , and Emotion into the Technology Acceptance Model," Inf. Syst. Res., vol. 11, no. 4, pp. 342-365, 2000. https://doi.org/10.1287/isre.11.4.342.11872 
[27] V. Venkatesh and H. Bala, "Technology acceptance model 3 and a research agenda on interventions," Decis. Sci., vol. 39, no. 2, pp. 273-315, 2008. https://doi.org/10.1111/j.15405915.2008.00192.x

[28] D. Martinho, E. Santos, M. I. Miguel, and D. Cordeiro, "Factors that influence the adoption of postgraduate online courses," Int. J. Emerg. Technol. Learn., vol. 13, no. 12, pp. 123-141, 2018. https://doi.org/10.3991/ijet.v13i12.8864

[29] V. Venkatesh, J. Thong, and X. Xu, "Consumer acceptance and user of information technology: Extending the unified theory of acceptance and use of technology," MIS Q., vol. 36, no. 1, pp. 157-178, 2012. https://doi.org/10.2307/41410412

[30] S. F. Persada, B. A. Miraja, and R. Nadlifatin, "Understanding the generation $z$ behavior on D-learning: A Unified Theory of Acceptance and Use of Technology (UTAUT) approach,” Int. J. Emerg. Technol. Learn., vol. 14, no. 5, pp. 20-33, 2019. https://doi.org/10. $\underline{\text { 3991/ijet.v14i05.9993 }}$

\section{$7 \quad$ Authors}

I Dewa Gede Rat Dwiyana Putra is a doctoral candidate who studies at the Doctorate program in English Language Teaching (ELT) of Universitas Negeri Malang, East Java, Indonesia. He is a lecturer at Institut Hindu Dharma Negeri Denpasar, Bali, Indonesia. His research focuses on ICT and writing.

Ali Saukah is a senior professor at the doctorate program in English Language Teaching (ELT) of State University of Malang. His research interests include English teaching curriculum, assessment, teacher professional development, and journal publication writing.

Yazid Basthomi is a professor at the doctorate program in English Language Teaching (ELT) of State University of Malang, Indonesia. His research interests mainly focus on applied linguistics, ICT, and Writing.

Enny Irawati is a senior lecturer at the doctorate program in English Language Teaching (ELT) of State University of Malang, Indonesia. Her main research interests are on Teaching English as a Foreign Language (TEFL), writing, and learning autonomy.

Article submitted 2019-06-20. Resubmitted 2019-12-03. Final acceptance 2019-12-05. Final version published as submitted by the authors. 